\title{
PROJECT VALUE-ADDING OPTIMIZATION OF PROJECT-BASED SUPPLY CHAIN UNDER DYNAMIC REPUTATION INCENTIVES
}

\author{
Lai, X. D. .; Wu, G.-D. ; Shi, J. G. ${ }^{* *}$; Wang, H. M. ${ }^{* * *} \&$ Kong, Q. S. ${ }^{* *}$ \\ * Jiangxi University of Finance \& Economics, Nanchang, 330013, Jiangxi, China \\ ${ }^{* *}$ School of Economics \& Management, Tongji University, Shanghai, 200092, China \\ ${ }^{* * *}$ Dalian University of Technology, Dalian 116024, China \\ E-Mail: tylerlai@126.com,gd198410@126.com,sjg126com@126.com,whm715@126.com, \\ kongqshan@gmail.com ( ${ }^{\#}$ Corresponding author)
}

\begin{abstract}
On the basis of equal cooperation between project-based enterprises, the project-based supply chain cross-organizational dynamic reputation incentives model was established in consideration of the implicit reputation factors to the contractor's incentive influence, and the impaction between control objective effect level, bargaining power and project value-adding was detailed analysed, especially the effective equilibrium condition for reputation incentive effects. Thus compared the analysis conclusions with project-based supply chain incentive model which single considering explicit benefit incentive, and verified the rationality and applicability of the project-based supply chain cross-organizational dynamic reputation incentives model through related digital simulation. The results reflects that, whether the linear relationship between duration and quality exists or not, the project management enterprise resorting to adjust project object objective incentive intensity and implementing reputation incentive strategy could not only achieve project value-adding maximization, but also realize net earnings Pareto improvement.

(Received, processed and accepted by the Chinese Representative Office.)
\end{abstract}

Key Words: Project-Based Supply Chain, Reputation Incentives, Project Control Objective, Project Value-Adding

\section{INTRODUCTION}

Compared with general manufacturing industry, construction industry has the features of high discreteness, low efficiency, over cost and duration, and remarkable conflicts [1-3]. As an innovative project management mode, Project-based Supply Chain, based on system theory, provides a new way of solving the above problems [4]. The cross-organizational cooperative innovation of project-based supply chain is an effective method of improving project performance and realizing project value-adding. However, due to the immanent features of construction projects, cross-organizational cooperative innovation of project-based supply chain tends to present temporality, dynamics and frequentations [5]. The success of cross-organizational cooperative innovation of project-based supply chain not only depends on internal factors of project-based organizations, including their level of effort and aptitude, but also is under influence of interactive decision making factors, such as the trust among project-based organizations and their reputation and control power [6]. In practice of cross-organizational cooperative innovation of project-based supply chain, project-based organizations always gain more earnings but block the realization of project value adding if they adopt fraud or abstain from an act strategy instead of focusing on reputation when neither effective incentive mechanisms nor market credit system exists [7]. Graafland (2004) studied construction projects in Netherland and found that reputation incentives help to avoid those behaviors lowering project value-adding within fierce market competition [8]. In areas of venture capital, online exchange, public management and wireless ad-hoc networks, similar 
conclusions were reached that under normal market credit environment, by constructing a reputation mechanism that binds agents' behaviours in long term, moral risks could be reduced [9-12]. With the theory of supply chain management being put into practice in construction projects, innovative management modes emerge in large numbers and incentive-based contracts get more and more preference from managers. As a result, contract design receives more attention from scholars [13-15]. As people's understanding of project cooperative innovation goes deeper and deeper, contract design gradually transforms from the style of considering explicit benefit incentives only to the style with combined consideration of explicit benefit incentives and implicit reputation incentives [16-17]. As a long-lasting incentive mechanism, reputation incentives provide sustained incentives and constraints both during operational period and post-operation period, serving as a fundamental way of avoid project-based organizations' moral risks in the long run [18].

For one certain project-based supply chain, the supply chain alliance disband when the project is completed and delivered, offering limited time for cooperation among project-based organizations. However, when considering the whole construction industry, cooperation among project-based organizations lasts indefinitely, making it particularly important to design a reward and punishment system that satisfies all sides' interest appeal and promote their cooperative relationship in project-based supply chain cross-organizational cooperative innovation [19]. Therefore, this paper assumes that in project-based supply chain cross-organizational cooperative innovation, the cooperative relationship among project-based organizations, once built, do not change during the whole construction process. In addition, it is supposed that we can determine effectively project-based organizations' behaviour choices in the future by investigating the influence of the quality of their cooperation on some specific control objective of the project [20-22]. Based on the above assumptions, this paper, from a comprehensive perspective of project value-adding, chose project management companies and contractors, the two major project-based organizations, as objects of study. We divided project-based supply chain cross-organizational cooperative innovation into two stages, and built a dynamic reputation incentive model combined consideration of explicit benefit incentives and implicit reputation incentives. We analysed the influence of contractors' level of effort, bargaining power, and effort cost rate of substitution on project value-adding sharing coefficient, with special attention on the effective equilibrium condition by which implicit reputation incentives can promote contractors' moral behaviours and also on the comparison between our conclusions with those under explicit benefit incentives.

\section{DESCRIPTION AND SOLUTIONS OF THE BASIC MODEL}

\subsection{Description of the basic model}

Considering the peculiarities of project-based supply chain cross-organizational cooperation, here we assume that there exist two equal project-based partners, i.e. one project management company and one contractor, the cooperative relationship between whom, once built, do not change throughout the whole construction process. The partners' cooperation in project-based supply chain is divided into $T$ stages. We assume that the project management company gets an estimation of the contractor's aptitude and level of effort at $t$ stage by the contractor's comprehensive performance before $t$ stage indicated by the weighted average of the a priori expectation and observations of its aptitude and level of effort. For simplicity, here we consider two cooperation stages $(T=2)$. Balancing the duration and quality objectives, we make for assumptions as following:

(1) At $t$ stage, the contractor's levels of effort for project duration and quality control objectives are $a_{t}$ and $b_{t}$ respectively with $\operatorname{cov}\left(a_{t}, b_{t}\right)=0, a_{t} \geq 0, b_{t} \geq 0$. The value-adding 
function of the project-based supply chain is expressed as eq. (1).

$$
q_{t}=\eta+A a_{t}+B b_{t}+\theta_{t}(t=1,2)
$$

In eq. (1), $A$ and $B$ are the output coefficients of the levels of effort into duration and quality objectives; $\eta$ is the contractor's monetization aptitude which is time-independent; $\theta_{t}$ denotes the impacts of extraneous random factors such as the uncertainties of technology and market on project output. Here we suppose that both $\eta$ and $\theta_{t}$ follow normal distribution with $\eta \sim N\left(0, \tau \sigma^{2}\right), \theta_{t} \sim N\left[0,(1-\tau) \sigma^{2}\right]$ where $\tau=\frac{\operatorname{var}(\eta)}{\operatorname{var}(\eta)+\operatorname{var}\left(\theta_{t}\right)}, \theta_{t}$ are mutually independent, and $\eta$ and $\theta_{t}$ are irrelevant.

(2) The contractor's effort cost function is $C\left(a_{t}, b_{t}\right)$, which is the strictly monotone increasing function of its levels of effort, i.e. $a_{t}$ and $b_{t}$, and the marginal cost of levels of effort is monotone increasing.

$$
C\left(a_{t}, b_{t}\right)=\frac{1}{2} \eta\left(a_{t}^{2}+2 k a_{t} b_{t}+b_{t}^{2}\right) \quad(t=1,2)
$$

In eq. (2), $k(-1 \leq k \leq 1)$ is the marginal cost rate of substitution of levels of effort into control objectives, that is the influence of raising the level of effort in one control objective on the marginal cost of realizing the another control objective. If $k=1$, the levels of effort into project duration and quality can be totally substituted by each other; If $k=-1$, the levels of effort into project duration and quality are completely complementary.

(3) The project management company offers the contractor linear contract compensation as eq. (3) shows.

$$
w_{t}=\alpha_{t}+\beta_{t} q_{t} \quad(t=1,2)
$$

In eq. (3), $\alpha_{t}$ is the fixed compensation for the contractor at $t$ stage which is assumed as a constant; $\beta_{t}\left(0 \leq \beta_{t} \leq 1\right)$ is the project value-adding sharing coefficient. According to the theory of reputation mechanism, at the second stage, the project management company estimates the contractor's aptitude $E\left(\eta \mid q_{1}\right)$ in project control objectives through investigating the project value-adding at the first stage, and determines the compensation $w_{2}$ for the contractor at the second stage.

(4) The project management company is risk central while the contractor is a risk averter with risk aversion extent being $\rho$ and the discount rate being $\delta_{0}$. Then we come to the following relations:

$\operatorname{var}\left(q_{t}\right)=\sigma^{2}, E\left(\eta \mid q_{1}\right)=\tau\left(q_{1}-A \hat{a_{1}}-B \hat{b_{1}}\right), E\left(q_{2} \mid q_{1}\right)=A \hat{a_{2}}+B \hat{b_{2}}+E\left(\eta \mid q_{1}\right), \operatorname{var}\left(q_{2} \mid q_{1}\right)=\left(1-\tau^{2}\right) \sigma^{2}$

Here, $\hat{a}_{t}$ and $\hat{b}_{t}$ are the project management company's expects of the contractor's levels of effort into duration and quality. So we get the certainty equivalence of the project management company and the contractor and the whole project value-adding, eq. (4).

$$
\left\{\begin{array}{l}
U=E\left(q_{1}\right)-E\left(w_{1}\right)+\delta\left[E\left(q_{2}\right)-E\left(w_{2}\right)\right] \\
\left.V=E\left(w_{1}\right)-C\left(a_{1}, b_{1}\right)+\delta\left[E\left(w_{2}\right)-C\left(a_{2}, b_{2}\right)\right]-\frac{1}{2} \rho \operatorname{var}\left(w_{1}+\delta w_{2}\right)\right] \\
U+V=E\left(q_{1}\right)-C\left(a_{1}, b_{1}\right)+\delta\left[E\left(q_{2}\right)-C\left(a_{2}, b_{2}\right)\right]-\frac{1}{2} \rho \operatorname{var}\left(w_{1}+\delta w_{2}\right)
\end{array}\right.
$$

The project management company aims at maximizing the project value-adding by choosing reasonable $\alpha_{t}$ and $\beta_{t}$, which is expressed as following:

$$
\max _{\alpha_{t}, \beta_{t} \wedge a_{t} \wedge b_{t}} E\left(q_{1}\right)-C\left(a_{1}, b_{1}\right)+\delta\left[E\left(q_{2}\right)-C\left(a_{2}, b_{2}\right)\right]-\frac{1}{2} \rho \operatorname{var}\left(w_{1}+\delta w_{2}\right)
$$




$$
\text { s.t. }\left\{\begin{array}{l}
\left.E\left(w_{1}\right)-C\left(a_{1}, b_{1}\right)+\delta\left[E\left(w_{2}\right)-C\left(a_{2}, b_{2}\right)\right]-\frac{1}{2} \rho \operatorname{var}\left(w_{1}+\delta w_{2}\right)\right] \geq \bar{V} \\
\overline{V_{2}}=\gamma_{2}\left(U_{2}+V_{2}\right) \\
\max _{\alpha_{t} \beta_{t} a_{t} b_{t}} E\left(q_{1}\right)-E\left(w_{1}\right)+\delta\left[E\left(q_{2}\right)-E\left(w_{2}\right)\right] \\
\left.\max _{\alpha_{t} \wedge \beta_{t} a_{t} b_{t}} E\left(w_{1}\right)-C\left(a_{1}, b_{1}\right)+\delta\left[E\left(w_{2}\right)-C\left(a_{2}, b_{2}\right)\right]-\frac{1}{2} \rho \operatorname{var}\left(w_{1}+\delta w_{2}\right)\right]
\end{array}\right.
$$

\subsection{Solution for the basic model}

At the second stage, the certainty equivalence of the project management company and the contractor are shown as eq. (7).

$$
\left\{\begin{array}{l}
V_{2}=\alpha_{2}+\beta_{2}\left[A \hat{a_{2}}+B \hat{b_{2}}+\tau\left(q_{1}-A \hat{a_{1}}-B \hat{b_{1}}\right)\right]-\frac{1}{2} \eta\left(a_{2}^{2}+2 k a_{2} b_{2}+b_{2}^{2}\right)-\frac{1}{2} \rho\left(1-\tau^{2}\right) \beta_{2}^{2} \sigma^{2} \\
U_{2}=\left(1-\beta_{2}\right)\left[A \hat{a_{2}}+B \hat{b_{2}}+\tau\left(q_{1}-A \hat{a_{1}}-B \hat{b_{1}}\right)\right]-\alpha_{2} \\
U_{2}+V_{2}=\left[A \hat{a_{2}}+B \hat{b_{2}}+\tau\left(q_{1}-A \hat{a_{1}}-B \hat{b_{1}}\right)\right]-\frac{1}{2} \eta\left(a_{2}^{2}+2 k a_{2} b_{2}+b_{2}^{2}\right)-\frac{1}{2} \rho\left(1-\tau^{2}\right) \beta_{2}^{2} \sigma^{2}
\end{array}\right.
$$

At this stage, the project management company provides incentives for the contractor by choosing proper $\alpha_{2}$ and $\beta_{2}$ to maximize the project value-adding, while the contractor, under that incentive mechanism, will choose proper $a_{2}$ and $b_{2}$ so as to maximize its benefits and ensure the benefits not lower than its retained income. The above optimization problem can be expressed by eqs. (8) and (9).

$$
\begin{aligned}
\max _{2, \beta_{2}, a_{2}, b_{2}}\left[A \hat{a}_{2}+B \hat{b_{2}}+\tau\left(q_{1}-A \hat{a}_{1}-B \hat{b}_{1}\right)\right]-\frac{1}{2} \eta\left(a_{2}^{2}+2 k a_{2} b_{2}+b_{2}^{2}\right)-\frac{1}{2} \rho\left(1-\tau^{2}\right) \beta_{2}^{2} \sigma^{2} \\
\left\{\begin{array}{l}
V_{2} \geq \overline{V_{2}} \\
\overline{V_{2}}=\gamma_{2}\left(U_{2}+V_{2}\right) \\
\max _{\alpha_{2}, \beta_{2} 、 a_{2}, b_{2}} U_{2} \\
\max _{\alpha_{2}, \beta_{2}, a_{2} 、 b_{2}} V_{2}
\end{array}\right.
\end{aligned}
$$

Substituting eq. (7) into eq. (9), we get eq. (10).

$$
\alpha_{2}=\left(\gamma_{2}-\beta_{2}\right)\left[A \hat{a}_{2}+B \hat{b}_{2}+\tau\left(q_{1}-A \hat{a}_{1}-B \hat{b_{1}}\right)\right]+\frac{1}{2}\left(1-\gamma_{2}\right) \eta\left(a_{2}^{2}+2 k a_{2} b_{2}+b_{2}^{2}\right)+\frac{1}{2} \rho\left(1-\gamma_{2}\right)\left(1-\tau^{2}\right) \beta_{2}^{2} \sigma^{2}
$$

Since $\left(\gamma_{2}-\beta_{2}\right)\left[A \hat{a_{2}}+B \hat{b_{2}}+\tau\left(q_{1}-A \hat{a_{1}}-B \hat{b_{1}}\right)\right]=\left(\gamma_{2}-\beta_{2}\right) E\left(\eta \mid q_{1}\right)$, it is clear that reputation incentive mechanism works by influencing the contractor's benefits at current stage $(t=2)$ based on its comprehensive performance at the previous stage $(t=1)$. When $\gamma_{2}>\beta_{2}$, the increase of the contractor's levels of effort helps add its benefits and raise the project management company's expectation of its performance. When $\gamma_{2}<\beta_{2}$, the contractor will choose to lower its levels of effort. Therefore, if the contract or expects more benefits, it will try to raise its bargaining power. Since the second stage $(t=2)$ is the last stage of the cooperation, the contractor's performance at that stage pose no effect on its benefits later. As a result, given $\alpha_{2}$ and $\beta_{2}$ we have $a_{2}=\hat{a}_{2}$ and $b_{2}=\hat{b}_{2}$. Then the first-order condition for the above problem is: 


$$
\left\{\begin{array}{l}
\frac{\partial V_{2}}{\partial a_{2}}=A \beta_{2}-\eta\left(a_{2}+k b_{2}\right)=0 \\
\frac{\partial V_{2}}{\partial b_{2}}=B \beta_{2}-\eta\left(b_{2}+k a_{2}\right)=0
\end{array}\right.
$$

The solution is:

$$
\left\{\begin{array}{l}
a_{2}=\frac{(A-B k) \beta_{2}}{\eta\left(1-k^{2}\right)} \\
b_{2}=\frac{(B-A k) \beta_{2}}{\eta\left(1-k^{2}\right)}
\end{array}\right.
$$

Substituting eq. (12) to eq. (8), we get the first-order condition of the optimized project-based supply chain cross-organizational incentives as following:

$$
\frac{\partial\left(U_{2}+V_{2}\right)}{\partial \beta_{2}}=0
$$

Since $\frac{\partial^{2}\left(U_{2}+V_{2}\right)}{\partial\left(\beta_{2}\right)^{2}}=-\frac{A^{2}+B^{2}-2 A B k}{\eta\left(1-k^{2}\right)}-\rho\left(1-\tau^{2}\right) \sigma^{2} \leq 0$, there exists $\beta_{2}$ that maximizes the project value-adding $\left(U_{2}+V_{2}\right)$. By substituting $\frac{\partial a_{2}}{\partial \beta_{2}}$ and $\frac{\partial b_{2}}{\partial \beta_{2}}$, we get the solution of $\beta_{2}$ :

$$
\beta_{2}=\frac{A^{2}+B^{2}-2 A B k}{A^{2}+B^{2}-2 A B k+\rho \eta\left(1-\tau^{2}\right)\left(1-k^{2}\right) \sigma^{2}}
$$

Substituting eqs. (10), (12) and (14) into eqs. (4), (5) and (6) respectively, and we get the first-order optimization problem of the project-based supply chain cross-organizational reputation incentives.

$$
\begin{aligned}
& \max _{\alpha_{1}, \beta_{1} 、 a_{1} b_{1}} A \hat{a}_{1}+B \hat{b}_{1}-\frac{1}{2} \eta\left(a_{1}^{2}+2 k a_{1} b_{1}+b_{1}^{2}\right)+\delta\left[A \hat{a}_{2}+B \hat{b}_{2}+\tau\left(q_{1}-A \hat{a_{1}}-B \hat{b_{1}}\right)\right. \\
& \left.-\frac{1}{2} \eta\left(a_{2}^{2}+2 k a_{2} b_{2}+b_{2}^{2}\right)\right]-\frac{1}{2} \rho\left[\beta_{1}^{2}+2 \delta \tau \beta_{1} \beta_{2}+\delta^{2} \beta_{2}^{2}\left(1-\tau^{2}\right)\right] \sigma^{2} \\
& \left\{\begin{array}{l}
V \geq \bar{V} \\
\bar{V}=\gamma_{1}(U+V) \\
\max _{\alpha_{1} \cdot \beta_{1}>a_{1} b_{1}} U \\
\max _{\alpha_{1}>\beta_{1}>a_{1} \cdot b_{1}} V
\end{array}\right.
\end{aligned}
$$

So, at the equilibrium of the project-based supply chain cross-organizational reputation incentives, we come to eq. (17).

$$
\begin{aligned}
\alpha_{1}+\delta \alpha_{2}= & \left(\gamma_{1}-\beta_{1}\right) A \hat{a_{1}}+B \hat{b_{1}}+\delta\left(\gamma_{1}-\beta_{1}\right)\left[A \hat{a_{2}}+B \hat{b_{2}}+\tau\left(q_{1}-A \hat{a_{1}}-B \hat{b_{1}}\right)\right]+\left(1-\gamma_{1}\right)\left[\frac{1}{2} \eta\left(a_{1}^{2}+2 k a_{1} b_{1}+b_{1}^{2}\right)\right. \\
& \left.+\frac{1}{2} \delta \eta\left(a_{2}^{2}+2 k a_{2} b_{2}+b_{2}^{2}\right)\right]+\frac{1}{2}\left(1-\gamma_{1}\right) \rho\left[\beta_{1}^{2}+2 \delta \tau \beta_{1} \beta_{2}+\delta^{2} \beta_{2}^{2}\left(1-\tau^{2}\right)\right] \sigma^{2}
\end{aligned}
$$

Substituting eq. (17) into the contractor's certainty income $V$, we get its first-order condition as eq. (18) shows.

$$
\left\{\begin{array}{l}
\frac{\partial V}{\partial a_{1}}=A \beta_{1}+A \delta \tau\left(\gamma_{1}-\beta_{2}\right)-\eta\left(a_{1}+k b_{1}\right)=0 \\
\frac{\partial V}{\partial b_{1}}=B \beta_{1}+B \delta \tau\left(\gamma_{1}-\beta_{2}\right)-\eta\left(b_{1}+k a_{1}\right)=0
\end{array}\right.
$$

The solution is: 


$$
\left\{\begin{array}{l}
a_{1}=\frac{(A-B k)\left[\beta_{1}+\delta \tau\left(\gamma_{1}-\beta_{2}\right)\right]}{\eta\left(1-k^{2}\right)} \\
b_{1}=\frac{(B-A k)\left[\beta_{1}+\delta \tau\left(\gamma_{1}-\beta_{2}\right)\right]}{\eta\left(1-k^{2}\right)}
\end{array}\right.
$$

Substituting eq. (19) into eq. (15), we get the first-order condition of the optimized project-based supply chain cross-organizational incentives as shown in eq. (20).

$$
\frac{\partial(U+V)}{\partial \beta_{1}}=0
$$

Since $\frac{\partial^{2}(U+V)}{\partial\left(\beta_{1}\right)^{2}}=-\frac{A^{2}+B^{2}-2 A B k}{\eta\left(1-k^{2}\right)}-\rho \sigma^{2} \leq 0$, there exists $\beta_{1}$ that maximizes the project value-adding $(U+V)$. We substitute $\frac{\partial a_{1}}{\partial \beta_{1}}$ and $\frac{\partial b_{1}}{\partial \beta_{1}}$ into eq. (20) and $\beta_{1}$ is solved.

$$
\beta_{1}=\frac{\left(A^{2}+B^{2}-2 A B k\right)\left(1-\delta \tau \gamma_{1}\right)+\delta \tau \beta_{2}\left[\left(A^{2}+B^{2}-2 A B k\right)-\rho \eta\left(1-k^{2}\right) \sigma^{2}\right]}{A^{2}+B^{2}-2 A B k+\rho \eta\left(1-k^{2}\right) \sigma^{2}}
$$

\section{MODEL ANALYSIS}

Conclusion 1: Comparing eqs. (12) and (19), we find that the relationship between the contractor's levels of effort into duration and quality objectives $\left(a_{2}\right.$ and $\left.b_{2}\right)$ and those at the first stage $\left(a_{1}\right.$ and $\left.b_{1}\right)$ depends on $\delta \tau\left(\gamma_{1}-\beta_{2}\right)$. Given the same project value-adding sharing coefficient at each stage, if $\gamma_{1}>\beta_{2}$ we have $a_{1}>a_{2}$ and $b_{1}>b_{2}$, but if $\gamma_{1}<\beta_{2}$ we have $a_{1}<a_{2}$, $b_{1}<b_{2}$, which means significant influence of reputation mechanism on the contractor's levels of effort into control objectives. Here, we see $\delta \tau \gamma_{1}$ as reputation effects while $\delta \tau \beta_{2}$ as ratchet effects. Therefore, the combined contribution of reputation effects and ratchet effects offers effective reputation incentives, and $\gamma_{1}>\beta_{2}$ is the effective equilibrium condition for the reputation incentive mechanism.

Conclusion 2: With the assumption of $a_{t}>0$ and $b_{t}>0(t=1,2)$, the contractor's levels of effort into control objectives increase as the project management company provides bigger optimal incentive coefficients.

The optimal incentive coefficient provided by the project management company poses impacts on the contractor's levels of effort into control objectives, but the extent of the impacts vary with transformation cost changes.

Conclusion 3: When $\gamma_{1}>2 \beta_{2}$, if the discount factor is big enough or the contractor's patience is great enough (bigger $\delta$ ), the project management company will lower the project value-adding share for the contractor, which enhances reputation effects but lessen ratchet effects and thus increases the contractor's levels of effort into control objectives. On the other hand, when $\gamma_{1}<2 \beta_{2}$, the project management company will lift the project value-adding share for the contractor, which lessens reputation effects but magnifies ratchet effects and thus decreases the contractor's levels of effort into control objectives.

When $\gamma_{1}>\frac{2\left(A^{2}+B^{2}-2 A B k\right)\left[\left(A^{2}+B^{2}-2 A B k\right)+\rho \eta\left(1+\tau^{2}\right) \sigma^{2}\right]}{\left[A^{2}+B^{2}-2 A B k+\rho \eta\left(1-\tau^{2}\right)\left(1-k^{2}\right) \sigma^{2}\right]^{2}}$, with the uncertainty of the contractor's aptitude being bigger (bigger $\tau$ ), the contractor will raise its levels of effort into control objectives in order to increase the project management company's expectation of its capabilities, thus magnifying reputation effects but weakening ratchet effects. When $\gamma_{1}<\frac{2\left(A^{2}+B^{2}-2 A B k\right)\left[\left(A^{2}+B^{2}-2 A B k\right)+\rho \eta\left(1+\tau^{2}\right) \sigma^{2}\right]}{\left[A^{2}+B^{2}-2 A B k+\rho \eta\left(1-\tau^{2}\right)\left(1-k^{2}\right) \sigma^{2}\right]^{2}}$, with the uncertainty of the contractor's aptitude being smaller (smaller $\tau$ ), the contractor will lower its levels of effort into control objectives in order to decrease the project management company's expectation of its 
capabilities, thus lessening reputation effects but promoting ratchet effects.

Conclusion 4: At the equilibrium of project-based supply chain cross-organizational dynamic reputation incentives, the optimal incentive coefficient, either in the first stage or the second stage, provided for the contractor by the project management company is a monotone decreasing function of the contractor's risk aversion, which means the bigger risk aversion (bigger $\rho$ ) of the contractor, the fewer incentives (smaller $\beta_{i}$ ) provided by the project management company for the contractor.

\section{COMPARISON WITH THE EXPLICIT INCENTIVE MODEL WITHOUT CONSIDERATION OF REPUTATION MECHANISM}

\subsection{Description and solution for the explicit incentive model}

We assume that the output function of the project-based supply chain is $q=A a+B b+\theta$, where $q$ indicates the project value-adding caused by the contractor's effort into duration and quality objectives; $\theta$ denotes extraneous random factors' influence on the project output with assumption of $\operatorname{var}(q)=\sigma^{2}$. The effort cost function of the project management company is $C(a, b)=\frac{1}{2} \eta\left(a^{2}+2 k a b+b^{2}\right)$. The linear incentive contract provided by the project management company for the contractor is $w=\alpha+\beta q$. Suppose the project management company is risk central while the contractor is a risk averter with risk aversion extent being $\rho$, and we will get the function of the certainty equivalence of the project management company and the contractor and the project value-adding function are as following:

$$
\left\{\begin{array}{l}
V_{0}=\alpha+\beta(A a+B b)-\frac{1}{2} \eta\left(a^{2}+2 k a b+b^{2}\right)-\frac{1}{2} \rho \beta^{2} \sigma^{2} \\
U_{0}=(1-\beta)(A a+B b)-\alpha \\
U_{0}+V_{0}=A a+B b-\frac{1}{2} \eta\left(a^{2}+2 k a b+b^{2}\right)-\frac{1}{2} \rho \beta^{2} \sigma^{2}
\end{array}\right.
$$

To maximize the utility function, the optimal project value-adding sharing parameters $a, b$ and $k$ are decided by the problems below.

$$
\begin{aligned}
& \max _{a, \mathrm{~b}, \beta, \mathrm{k}} A a+B b-\frac{1}{2} \eta\left(a^{2}+2 k a b+b^{2}\right)-\frac{1}{2} \rho \beta^{2} \sigma^{2} \\
& \alpha+\beta(A a+B b)-\frac{1}{2} \eta\left(a^{2}+2 k a b+b^{2}\right)-\frac{1}{2} \rho \beta^{2} \sigma^{2} \geq \overline{V_{0}} \\
& \max _{a, \mathrm{~b} 、 \beta, \mathrm{k}}(1-\beta)(A a+B b)-\alpha \\
& \max _{a, \mathrm{~b}, \beta, \mathrm{k}} \alpha+\beta(A a+B b)-\frac{1}{2} \eta\left(a^{2}+2 k a b+b^{2}\right)-\frac{1}{2} \rho \beta^{2} \sigma^{2}
\end{aligned}
$$

The first-order condition of the problems above is below.

$$
\left\{\begin{array}{l}
\frac{\partial V_{0}}{\partial a}=A \beta-\eta(a+k b)=0 \\
\frac{\partial V_{0}}{\partial b}=B \beta-\eta(b+k a)=0
\end{array}\right.
$$

The solution is shown in eq. (25).

$$
\left\{\begin{array}{l}
a=\frac{(A-B k) \beta}{\eta\left(1-k^{2}\right)} \\
b=\frac{(B-A k) \beta}{\eta\left(1-k^{2}\right)}
\end{array}\right.
$$


Substituting eq. (25) into eq. (23), we get the first-order condition of the optimized project-based supply chain cross-organizational incentives.

Since $\frac{\partial^{2}\left(U_{0}+V_{0}\right)}{\partial(\beta)^{2}}=-\frac{A^{2}+B^{2}-2 A B k}{\eta\left(1-k^{2}\right)}-\rho \sigma^{2} \leq 0$, there exists $\beta$ that maximizes the project value-adding $\left(U_{0}+V_{0}\right)$. Substituting $\frac{\partial a}{\partial \beta}$ and $\frac{\partial b}{\partial \beta}$ and $\beta$ is solved.

$$
\beta=\frac{A^{2}+B^{2}-2 A B k}{A^{2}+B^{2}-2 A B k+\rho \eta\left(1-k^{2}\right) \sigma^{2}}
$$

\subsection{Comparison of conclusions between two models}

Conclusion 5: When considering the implicit incentives of reputation mechanism in project-based supply chain cross-organizational incentives, the contractor's project value-adding sharing coefficient at the first stage $\beta_{1}$ is smaller than the sharing coefficient $\beta$ without consideration of reputation mechanism, but when $\gamma_{1}>2 \beta_{2}$, the contractor's project value-adding sharing coefficient at the second stage $\beta_{2}$ is bigger than $\beta$. This means in some situations, the contractor who take its reputation seriously will increase its benefit during the multi-stage cooperation with the project management company, and the benefits are higher than those without consideration of reputation.

Conclusion 6: When considering the implicit incentives of reputation mechanism in project-based supply chain cross-organizational incentives, the contractor's levels of effort into control objectives at the first stage are higher than those under consideration of explicit incentives only. Similarly, if $\gamma_{1}>2 \beta_{2}$, the contractor's levels of effort into control objectives at the second stage is bigger than those under consideration of explicit incentives only. That means the combination of explicit and implicit incentives contributes to increase the contractor's levels of effort into control objectives, and the project management company should increase the project value-adding sharing coefficient given to the contractor so as to achieve the multi-objective coordination of the project-based supply chain and the Pareto improvement of the two partners' benefit goals.

\section{DATA SIMULATION AND NUMERICAL EXAMPLE}

\subsection{Data simulation}

To testify the applicability and rationality of the project-based supply chain cross-organizational dynamic reputation incentive model, we assume that 1) the variance of the impacts posed by extraneous factors is $\sigma^{2}=100 ; 2$ ) the contractor's effort cost coefficient is $\eta=100 ; 3$ ) the contractor's output efficiency coefficients of duration and quality objectives are the same, i.e. $A=B=100$. Then we can analyse the influence of marginal cost rate of substitution of the levels of effort $(k)$ and the contractor's bargaining power $\left(\gamma_{1}\right)$ on the project value-adding sharing coefficient and the contractor's levels of effort.

(1) We substitute the above data into eqs. (14), (21) and (26) and the expressions of $\beta, \beta_{1}$ and $\beta_{2}$ are as following. Given $\gamma_{1}=1$, the simulation results by Origin 8.5 are shown as Fig. 1 .

It is obvious in Fig. $1, \beta, \beta_{1}$ and $\beta_{2}$ are decreasing functions of marginal rates of substitution of the cost of effort into the project control objectives $(k)$, which indicates they decrease as $k$ increases. Also, it is seen that $\beta_{1}<\beta<\beta_{2}$.

(2) We substitute the above data into eqs. (12), (19) and (25) and the expressions of $a, a_{1}$ and $a_{2}$ are as following. Given $\gamma_{1}=1$, the simulation results by Origin 8.5 are shown as Fig. 2 . Obviously seen from Fig. 2, if related parameters are given, $a, a_{1}$ and $a_{2}$ are decreasing functions of marginal rates of substitution of the cost of effort into the project control objectives $(k)$, and decreasing $k$ as goes up. 


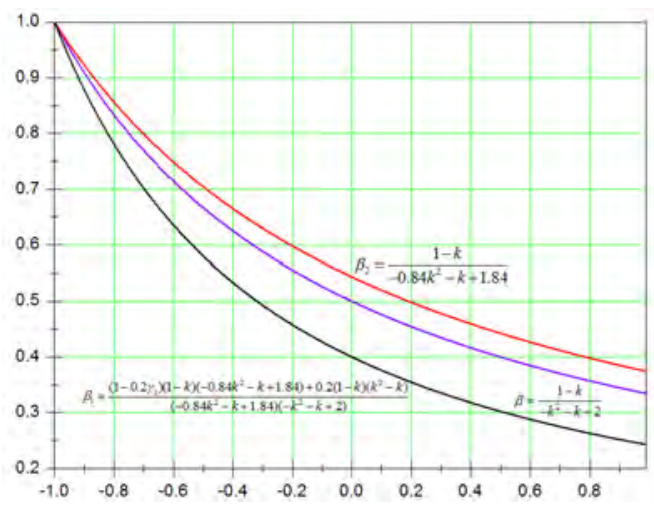

Figure 1: The relationship between marginal rates of substitution of the cost of effort into the project control objectives and the project value-adding sharing coefficient.

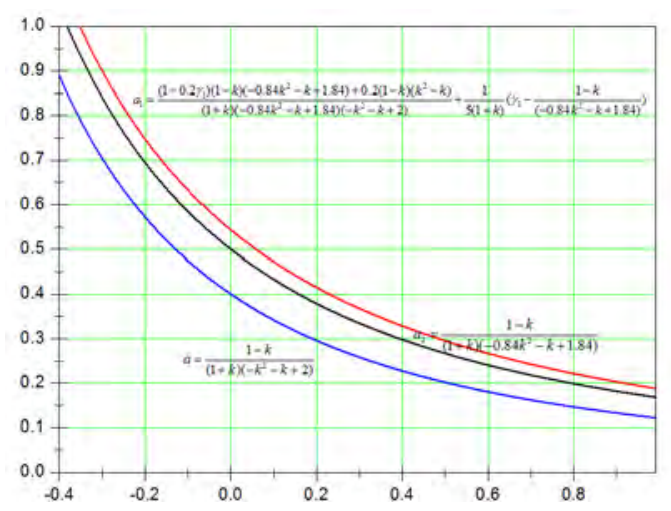

Figure 2: The relationship between marginal rates of substitution of the cost of effort into the project control objectives and the level of effort into the duration objective.

(3) To test the influence of discount rate $\delta$ and the contractor's uncertainty of its aptitude $\tau$ on the project value-adding sharing coefficient $\beta_{1}$, we substitute related data (except $\delta, \tau, \gamma_{1}$ and $k$ ) into eq. (21).

1) If $\tau=0.4$, given $\gamma_{1}=0.1, \gamma_{1}=0.4$ and $\gamma_{1}=0.8$ respectively, the simulation results by Origin 8.5 are shown as Fig. 3.

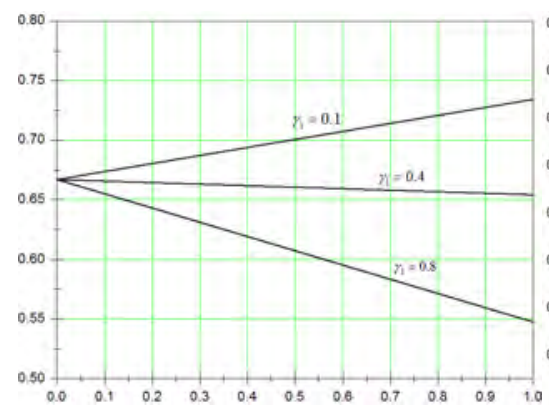

a) $k=-0.5$

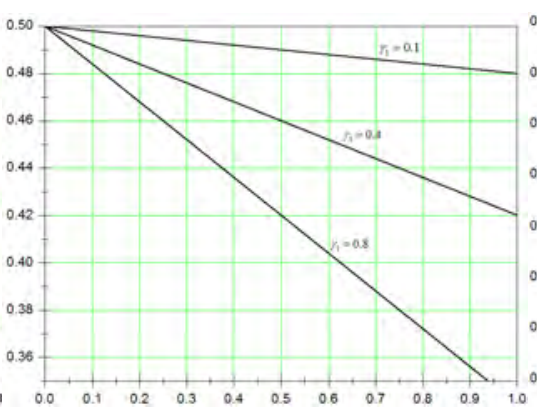

b) $k=0$

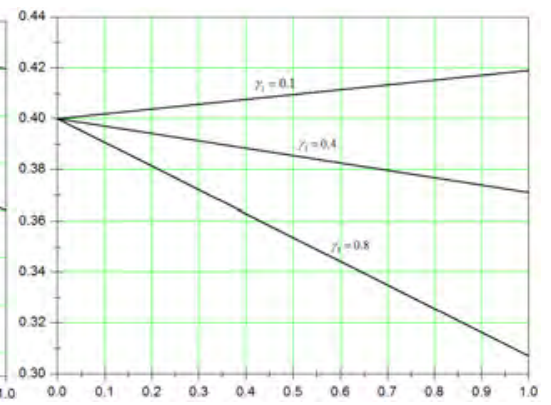

c) $k=0.5$

Figure 3: The relationship between $\delta$ and $\beta_{1}$ under different $\gamma_{1}$.

Substituting related data into $\frac{\partial \beta_{1}}{\partial \delta}$, we get the turning points of the monotonicity of $\beta_{1}$ under different $k: \gamma_{1}=0.352, \gamma_{1}=0$ and $\gamma_{1}=0.219$. In Fig. 3 , when $\gamma_{1}=0.1<0.352, \beta_{1}$ is an increasing function; when $\gamma_{1}=0.4,0.8>0.352, \beta_{1}$ decreases.

2) If $\delta=0.5$, given $\gamma_{1}=0.1, \gamma_{1}=0.4$ and $\gamma_{1}=0.8$, the simulation results by Origin 8.5 are as following. 


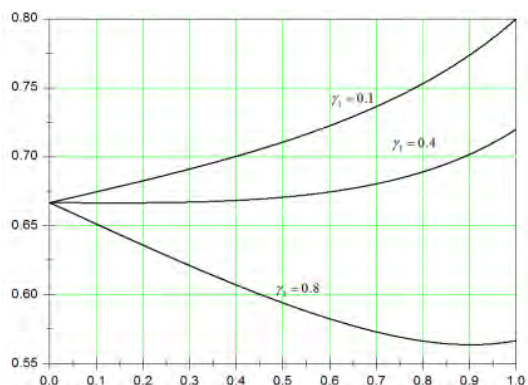

a) $k=-0.5$

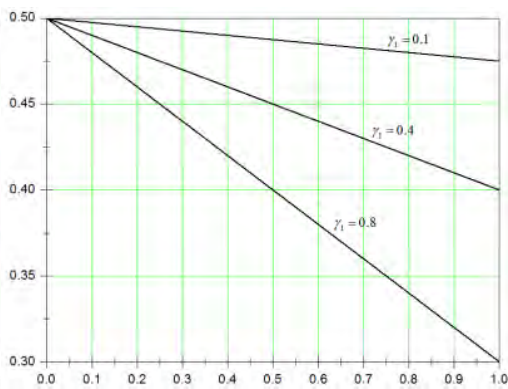

b) $k=0$

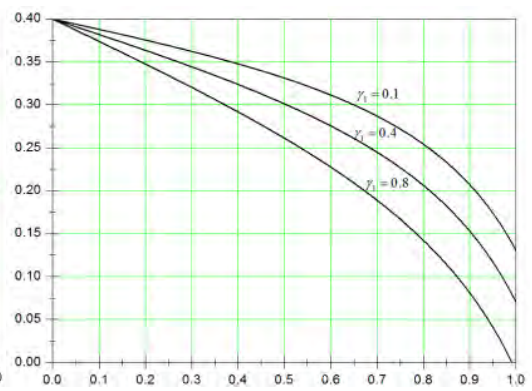

c) $k=0.5$

Figure 4: The relationship between $\tau$ and $\beta_{1}$ under different $\gamma_{1}$.

Substituting related data into $\frac{\partial \beta_{1}}{\partial \delta}$ in conclusion 3 , we get the turning points of the monotonicity of $\beta_{1}$ under different $k: \gamma_{1}=0.412, \gamma_{1}=0$ and $\gamma_{1}=0.097$. In Fig. 4 , when $\gamma_{1}=0.1$, $0.4<0.412, \beta_{1}$ is an increasing function; when $\gamma_{1}=0.8>0.412, \beta_{1}$ decreases. We find similar conclusions in Fig. 4. So the relationship between $\tau$ and $\beta_{1}$ in conclusion 3 is validated.

(4) Here we try to test the influence of discount rate $\delta$ and the contractor's uncertainty of its aptitude $\tau$ on the contractor's levels of effort into control objectives $\left(a_{1}\right.$ and $\left.b_{1}\right)$. With the assumption of $A=B$, we have $a_{1}=b_{1}$. Substituting related data (except $\delta, \tau, \gamma_{1}$ and $k$ ) into eq. (19), we get the expressions of $a_{1}$ under different $k$ as below.

1) If $\tau=0.4$, given $\gamma_{1}=0.1, \gamma_{1}=0.4$ and $\gamma_{1}=0.8$, the simulation results by Origin 8.5 are as following.

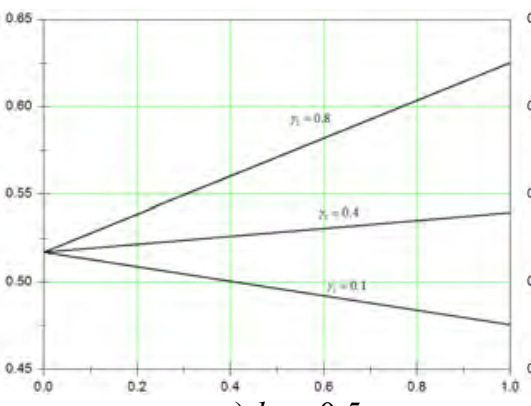

a) $k=-0.5$

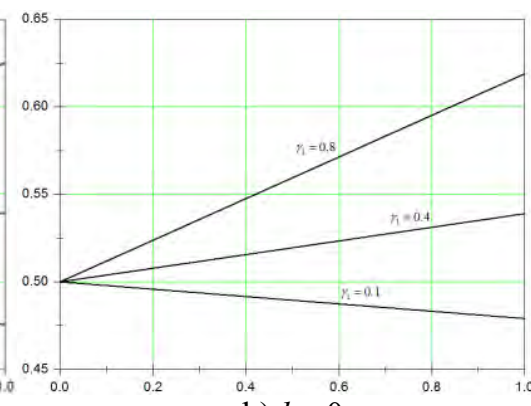

b) $k=0$

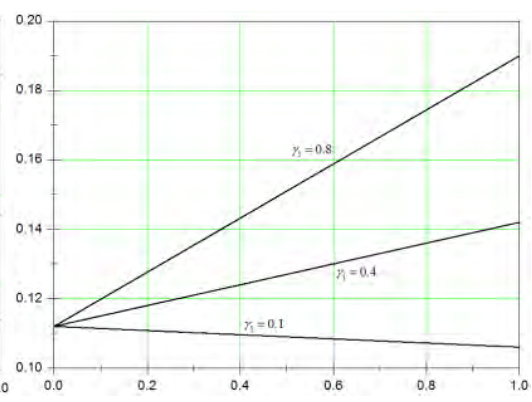

c) $k=0.5$

Figure 5: The relationship between $\delta$ and $a_{1}$ under different $\gamma_{1}$.

Substituting related data into $\frac{\partial a_{1}}{\partial \delta}$, we get the turning points of the monotonicity of $\beta_{1}$ under different $k: \gamma_{1}=0.294, \gamma_{1}=0.205$ and $\gamma_{1}=0.15$. In Fig. 5, when $\gamma_{1}=0.1<0.294, a_{1}$ is a decreasing function; when $\gamma_{1}=0.4,0.8>0.294, a_{1}$ increases. So the relationship between $\delta$ and $a_{1}$ in conclusion 3 is validated. In the same way, we can investigate the relationship between discount rate $\delta$ and the level of effort into the quality objective $\left(b_{1}\right)$. As for $\frac{\partial a_{1}}{\partial \delta}$, $\gamma_{1}=2 \beta_{2}$ is the turning point of the monotonicity of $a_{1}$. So given $k=-0.5,0,0.5, \beta_{2}$ will be $0.147,0.103$ and 0.075 , respectively. Therefore, from another perspective, we validate that $\beta_{2}$ is a decreasing function of $k$.

2) If $\delta=0.5$, given $\gamma_{1}=0.1, \gamma_{1}=0.4$ and $\gamma_{1}=0.8$, the simulation results by Origin 8.5 are as following.

Substituting related data into $\frac{\partial a_{1}}{\partial \tau}$ in conclusion 3 , we get the turning points of the monotonicity of $\beta_{1}$ under different $k: \gamma_{1}=0.367, \gamma_{1}=0.828$ and $\gamma_{1}=0.871$. In Fig. 6, when $\gamma_{1}=0.1<0.367, a_{1}$ is a decreasing function; when $\gamma_{1}=0.4,0.8>0.367, a_{1}$ increases. So the relationship between $\tau$ and $a_{1}$ in conclusion 3 is validated. In the same way, we can investigate the relationship between discount rate $\delta$ and the level of effort into the quality objective $\left(b_{1}\right)$. 


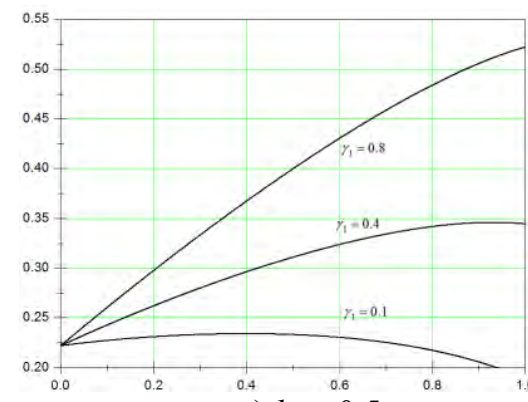

a) $k=-0.5$

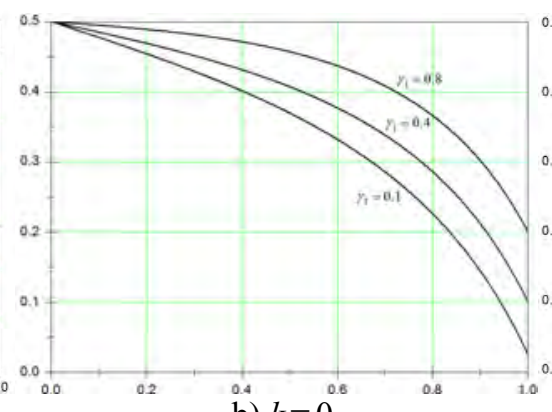

b) $k=0$

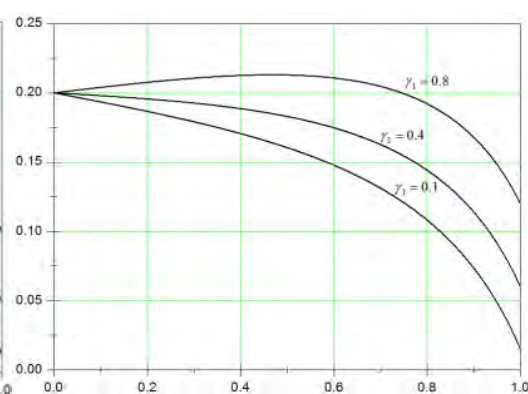

c) $k=0.5$

Figure 6: The relationship between $\tau$ and $a_{1}$ under different $\gamma_{1}$.

\subsection{A numerical example}

The related parameters are: $\eta=100, \rho=2, \tau=0.4, \delta=0.5$ and $A=B=100$. We analyse the influence of the marginal rates of substitution of the cost of effort into the project control objectives $(k)$ and the contractor's bargaining power $\left(\gamma_{1}\right)$ on the project value-adding. Based on the project-based supply chain cross-organizational dynamic reputation incentive model and the project-based supply chain cross-organizational explicit incentive model without reputation incentives, we get the results of parameters (Table I), with $k$ being $-0.5,0$ and 0.5 and $\gamma_{1}$, being $0,0.1,0.4,0.8$ and 1 .

Table I: The results of the numerical example.

\begin{tabular}{|c|c|c|c|c|c|c|}
\hline$\gamma_{1}$ & $k$ & $\left(\beta_{1}, \beta, \beta_{2}\right)$ & $\left(a_{1}, a, a_{2}\right)$ & $U_{0}+V_{0}$ & $U+V$ & Comparison of results \\
\hline \multirow{3}{*}{0} & -0.5 & $(0.536,0.545,0.704)$ & $(0.778,1.09,1.408)$ & 99.19 & 90.89 & \multirow{3}{*}{$\begin{array}{l}\gamma_{1}<\beta_{2} \quad \beta_{1}<\beta<\beta_{2} \\
a_{1}<a<a_{2} \quad a_{1} / \beta_{1}<a_{2} / \beta_{2}\end{array}$} \\
\hline & 0 & $(0.449,0.5,0.543)$ & $(0.288,0.5,0.543)$ & 25.00 & 8.32 & \\
\hline & 0.5 & $(0.282,0.286,0.442)$ & $(0.118,0.190,0.295)$ & 16.32 & 4.70 & \\
\hline \multirow{3}{*}{0.1} & -0.5 & $(0.510,0.545,0.704)$ & $(0.790,1.09,1.408)$ & 99.19 & 93.71 & \multirow{3}{*}{$\begin{array}{l}\gamma_{1}<\beta_{2} \quad \beta_{1}<\beta<\beta_{2} \\
a_{1}<a<a_{2} \quad a_{1} / \beta_{1}<a_{2} / \beta_{2}\end{array}$} \\
\hline & 0 & $(0.377,0.5,0.543)$ & $(0.327,0.5,0.543)$ & 25.00 & 10.69 & \\
\hline & 0.5 & $(0.261,0.286,0.442)$ & $(0.129,0.190,0.295)$ & 16.32 & 7.83 & \\
\hline \multirow{3}{*}{0.4} & -0.5 & $(0.459,0.545,0.704)$ & $(0.796,1.09,1.408)$ & 99.19 & 95.14 & \multirow{3}{*}{$\begin{array}{l}\gamma_{1}<\beta_{2} \quad \beta_{1}<\beta<\beta_{2} \\
a_{1}<a<a_{2} \quad a_{1} / \beta_{1}<a_{2} / \beta_{2}\end{array}$} \\
\hline & 0 & $(0.356,0.5,0.543)$ & $(0.353,0.5,0.543)$ & 25.00 & 12.46 & \\
\hline & 0.5 & $(0.224,0.286,0.442)$ & $(0.144,0.190,0.295)$ & 16.32 & 9.03 & \\
\hline \multirow{3}{*}{0.8} & -0.5 & $(0.426,0.545,0.704)$ & $(0.890,1.09,1.408)$ & 99.19 & 98.46 & \multirow{3}{*}{$\begin{array}{l}\gamma_{1}>\beta_{2} \quad \beta_{1}<\beta<\beta_{2} \\
a_{1}<a<a_{2} \quad a_{1} / \beta_{1}>a_{2} / \beta_{2}\end{array}$} \\
\hline & 0 & $(0.302,0.5,0.543)$ & $(0.390,0.5,0.543)$ & 25.00 & 15.21 & \\
\hline & 0.5 & $(0.220,0.286,0.442)$ & $(0.284,0.190,0.295)$ & 16.32 & 11.89 & \\
\hline \multirow{3}{*}{1} & -0.5 & $(0.319,0.545,0.704)$ & $(0.937,1.09,1.408)$ & 99.19 & 118.92 & \multirow{2}{*}{$\begin{array}{l}\gamma_{1}>\beta_{2} \quad \beta_{1}<\beta<\beta_{2} \\
a_{1}<a<a_{2} \quad a_{1} / \beta_{1}>a_{2} / \beta_{2}\end{array}$} \\
\hline & 0 & $(0.247,0.5,0.543)$ & $(0.493,0.5,0.543)$ & 25.00 & 24.30 & \\
\hline & 0.5 & $(0.169,0.286,0.442)$ & $(0.362,0.190,0.295)$ & 16.32 & 18.44 & $\begin{array}{ll}\gamma_{1}>2 \beta_{2} & \beta_{1}<\beta<\beta_{2} \\
a_{1}>a_{2}>a & a_{1} / \beta_{1}>a_{2} / \beta_{2}\end{array}$ \\
\hline
\end{tabular}

\section{CONCLUSIONS}

On the basis of equal cooperation among project-based enterprises, chose project management companies and contractors, the two major project-based organizations, as objects of study. In consideration of the contractor's reputation and its marginal rates of substitution of the cost of effort into the duration and quality objectives, we divided project-based supply chain cross-organizational cooperative innovation into two stages, and built a project-based supply chain cross-organizational dynamic reputation incentive model, by which the influence of the contractor's reputation and bargaining power and the marginal rates of substitution of the cost 
of effort into the project control objectives on the contractor's levels of effort, the project value-adding sharing coefficient and the rate of project value-adding.

We compared the results with those from the project-based supply chain explicit incentive model, and took data simulation and a numerical example for analysis. The results are as follows. (1) the reputation mechanism influences the contractor's benefits through adjusting its fixed compensation in the future, and thus influence its levels of effort into control objectives. However, in order to ensure the reputation effects, the negative impacts of ratchet effects should be lessened; (2) the marginal rates of substitution of the cost of effort into duration and quality objectives pose significant influence on the optimal value-adding sharing coefficient of the project-based supply chain. The bigger the marginal rates of substitution of the cost of effort into duration and quality objectives, the smaller the project value-adding sharing coefficient; (3) the contractor's bargaining power and the marginal rates of substitution of the cost of effort into the project control objectives pose different influence on the contractor's levels of effort into control objectives; (4) under certain circumstance, the introduction of the reputation mechanism into the project-based supply chain cross-organizational incentives offers greater incentive effects on the contractor, making it possible for the project management company to provide less project value-adding for the contractor but push it to devote more effort. (5) the contractor's aptitude and the discount rate have different influence on its levels of effort and the project value-adding sharing coefficient. The influence varies under different marginal rates of substitution of the cost of effort into the project control objectives.

This study shows that, in the project-based supply chain cross-organizational cooperation, combination of implicit reputation incentives and explicit benefit incentives, and the combination of long term and short term incentives, compared with the short term benefit incentives, are more applicable and more reasonable in promoting the trust among project participants. It should be noticed that the model in this paper is built under a series of hypothesis. Therefore, the actual objective of this study lies in putting forward some helpful suggestions for improve project-based organizations' cooperation by model analysis and offering a new way for the project-based supply chain cross-organizational cooperative innovation.

\section{ACKNOWLEDGEMENT}

This work was supported by National Natural Science Funds of China (Grant No. 71301065), University Social Sciences and Humanities Funds of Jiangxi Province (Grant No. JC1309, Grant No. JC1403), Scientific and technological research Funds of Department of Education of Jiangxi Province (Grant No. GJJ14341).

\section{REFERENCES}

[1] Vrijhoef, R.; Koskela, L. (2000). The four roles of supply chain management in construction, European Journal of Purchasing \& Supply Chain Management, Vol. 6, No. 3-4, 169-178, doi:10.1016/S0969-7012(00)00013-7

[2] Love, P. E. D.; Irani, Z.; Edwards, D. J. (2004). A seamless supply chain management model for construction, Supply Chain Management: An International Journal, Vol. 9, No. 1, 43-56, doi: $10.1108 / 13598540410517575$

[3] Xue, X. L.; Wang, Y. W.; Shen, Q. P.; Yu, X. G. (2007). Coordination mechanisms for construction supply chain management in the Internet environment, International Journal of Project Management, Vol. 25, No. 2, 150-157, doi:10.1016/j.ijproman.2006.09.006

[4] Ofori, G. (2000). Greening the construction supply chain in Singapore, European Journal of Purchasing \& Supply Chain Management, Vol. 6, No. 3-4, 195-206, doi:10.1016/S0969$\underline{7012(00) 00015-0}$ 
[5] Shi, J. G.; Wu, G. D.; Tang, D. Z. (2011). Project-based supply chain cross-organizational cooperative incentives mechanism based on knowledge flow, Soft Science, Vol. 25, No. 4, 44-49

[6] Englmaier, F.; Filipi, A.; Singh, R. (2010). Incentives, reputation and the allocation of authority, Journal of Economic Behavior \& Organization, Vol. 76, No. 2, 413-427, doi:10.1016/j.jebo. 2010.06.011

[7] Zhao, H. Y.; Yang, X.; Li, X. L. (2012). An incentive mechanism to reinforce truthful reports in reputation systems, Journal of Network and Computer Applications, Vol. 35, No. 3, 951-961, doi:10.1016/j.jnca.2011.03.011

[8] Graafland, J. J. (2004). Collusion, reputation damage and interest in code of conduct: The case of a Dutch construction company, Business Ethics: A European Review, Vol. 13, No. 2-3, 127-142, doi:10.1111/j.1467-8608.2004.00359.x

[9] Dasgupta, A.; Sarafidis, Y. (2009). Managers as administrators: Reputation and incentives, Journal of Economic Behavior \& Organization, Vol. 70, No. 1-2, 155-163, doi:10.1016/j.jebo. 2008.12.009

[10] Zacharia, G.; Moukas, A.; Maes, P. (2000). Collaborative reputation mechanisms for electronic marketplaces, Decision Support Systems, Vol. 29, No. 4, 371-388, doi:10.1016/S01679236(00)00084-1

[11] Maor, M. (2007). A scientific standard and an agency's legal independence: which of these reputation protection mechanisms is less susceptible to political moves?, Public Administration, Vol. 85, No. 4, 961-978, doi:10.1111/j.1467-9299.2007.00676.x

[12] Jaramillo, J. J.; Srikant, R. (2010). A game theory based reputation mechanism to incentivize cooperation in wireless ad hoc networks, Ad Hoc Networks, Vol. 8, No. 4, 416-429, doi:10.1016/ j.adhoc. 2009.10.002

[13] Cheung, S.-O., Ng, T. S. T.; Wong, S.-P.; Suen, H. C. H. (2003). Behavioral aspects in construction partnering, International Journal of Project Management, Vol. 21, No. 5, 333-343, doi:10.1016/S0263-7863(02)00052-2

[14] Schneeweiss, C.; Zimmer, K.; Zimmermann, M. (2004). The design of contracts to coordinate operational interdependencies within the supply chain, International Journal of Production Economics, Vol. 92, No. 1, 43-59, doi:10.1016/j.ijpe.2003.10.005

[15] Giannoccaro, I.; Pontrandolfo, P. (2004). Supply chain coordination by revenue sharing contracts, International Journal of Production Economics, Vol. 89, No. 2, 131-139, doi:10.1016/S09255273(03)00047-1

[16] Bubshait, A. A. (2003). Incentive/disincentive contracts and its effects on industrial projects, International Journal of Project Management, Vol. 21, No. 1, 63-70, doi:10.1016/S0263$\underline{7863(01) 00078-3}$

[17] Motawa, I.; Kaka, A. (2009). Modelling payment mechanisms for supply chain in construction, Engineering, Construction and Architectural Management, Vol. 16, No. 4, 325-336, doi:10.1108/ 09699980910970824

[18] Chen, J. H.; Ma, S. H. (2008). A dynamic reputation incentive model in construction supply chain, Long Beach $15^{\text {th }}$ International Conference on Management Science \& Engineering, Vol. I-II, No. 9, 385-392

[19] Matthews, J.; Pellew, L.; Phua, F.; Rowlinson, S. (2000). Quality relationships: partnering in the construction supply chain, International Journal of Quality \& Reliability Management, Vol. 17, No. 4-5, 493-510, doi:10.1108/02656710010371191

[20] Cheng, Y.; You, J. X. (2006). Qualitative simulation of engineering project collaboration performance in supply chain, China Civil Engineering Journal, Vol. 39, No. 2, 113-116

[21] Parrod, N.; Thierry, C.; Fargier, H., Cavaille, J. B. (2007). Cooperative subcontracting relationship within a project supply chain: A simulation approach, Simulation Modelling Practice and Theory, Vol. 15, No. 2, 137-152, doi:10.1016/j.simpat.2006.09.016

[22] Holmstrom, B.; Milgrom, P. (1991). Multitask principal-agent analyses: incentive contracts, asset ownership and job design, Journal of Law, Economics \& Organization, Vol. 7, No. 1 (special issue), 24-52, doi:10.1093/jleo/7.special_issue. 24 